\title{
Effects of limited moisture content and storing temperature on retrogradation of rice starch
}

\begin{abstract}
The objective of this study is to investigate the effects of limited moisture content and storing temperature on the retrogradation of rice starch. Starch was gelatinized in various moisture contents $(30-42 \%)$ and rice paste was stored at different temperatures $\left(4{ }^{\circ} \mathrm{C}, 15{ }^{\circ} \mathrm{C}, 30^{\circ} \mathrm{C}\right.$, $-18 / 30{ }^{\circ} \mathrm{C}$ and $4 / 30^{\circ} \mathrm{C}$ ). X-ray diffraction (XRD) analysis revealed that after retrogradation, the crystalline type of rice starch changed from A-type to B $+\mathrm{V}$ type. The B-type crystallinity of retrograded rice starch under $30^{\circ} \mathrm{C}$ was the highest among the five temperature conditions, and an increase in B-type crystallinity with increasing moisture content was observed. Differential scanning calorimetry (DSC) results revealed that rice starch retrogradation consists of recrystallization of amylopectin and amylose, and is mainly attributed to amylopectin. The higher moisture content was favorable for amylopectin recrystallization, whereas the moisture content had little effect on the amylose recrystallization. The optimal temperature for amylopectin and amylose recrystallization was $4{ }^{\circ} \mathrm{C}$ and $15{ }^{\circ} \mathrm{C}$, respectively. The amylopectin recrystallization enthalpy of rice starch stored at $4 / 30^{\circ} \mathrm{C}$ was mediated between $4{ }^{\circ} \mathrm{C}$ and $30{ }^{\circ} \mathrm{C}$ but always higher than that at $-18 / 30{ }^{\circ} \mathrm{C}$. On the whole, after being heated at $42 \%$ moisture content and stored at $4{ }^{\circ} \mathrm{C}$, rice starch showed the maximum total retrogradation enthalpy $(8.44 \mathrm{~J} / \mathrm{g})$.
\end{abstract}

Keyword: Rice starch; Retrogradation; Moisture content; Storing temperature 